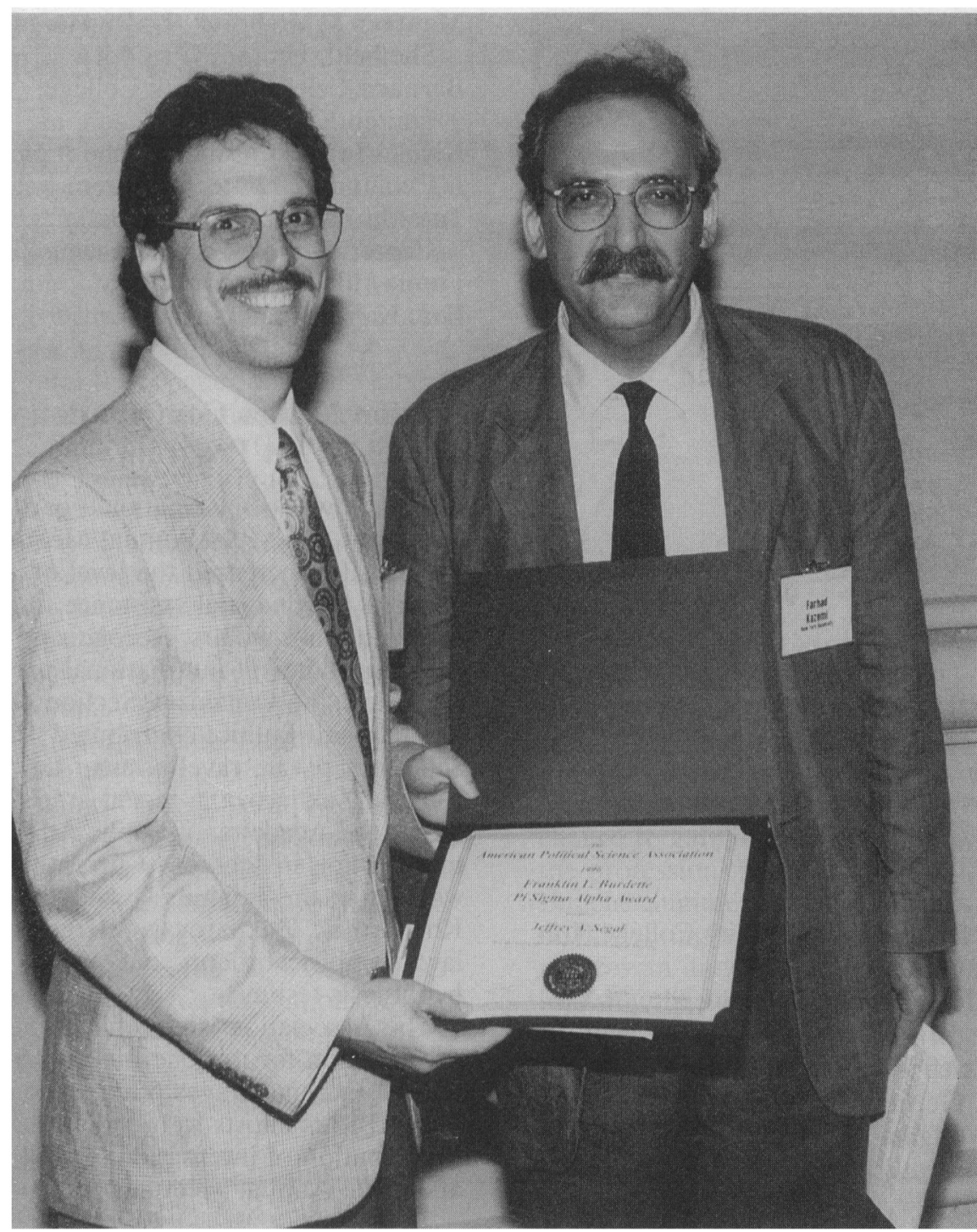

Farhad Kazemi, New York University, chair of the Franklin L. Burdette Pi Sigma Alpha Award for the best paper presented at the 1995 Annual Meeting honors the 1996 recipient, Jeffrey A. Segal, SUNY-Stony Brook, for his paper "Marksist (and Neo-Marksist) Models of Supreme Court Decision Making: Separation-of-Powers in the Positive Theory of Law and Courts."

workshops where political scientists and graduate students learned about teaching and research skills, developed computer expertise, and heard senior scholars reflect on the profession. Nearly 150 Annual Meeting attendees participated in this year's short course program.

Short courses this year included the Leading Scholar Series which featured Gabriel A. Almond and Heinz Eulau, both of Stanford University and both former APSA presidents. This session served as an extraordinary opportunity for graduate students to meet two high-profile political scientists and gain from their insight into the profession.

The program also included courses on the Internet and World Wide Web technologies and a course on databases available for legal research. Other courses offered opportunities to learn about teaching gender and politics, teaching citizen participation, and acting as a pre-law advisor to undergraduates. Workshops on defense and security in contemporary Asia, constitutional democracies, and California state politics in the 1990 s were also included in the program.

Plans for the 1997 Short Course Program are presently underway. Those interested in sponsoring short courses at the 1997 Annual Meeting should contact Rob Hauck, Deputy Director of APSA.

\section{Travel Grants Bring International Scholars to Meeting}

In an effort to assist international scholars participating at the annual meeting in San Francisco, the Association was able to secure travel funding for 50 scholars, including 28 senior scholars and 22 international students enrolled in american universities. A list of international grantees, their countries, and their U.S. affiliations follows:

Therese S. Gunawardena, University of Texas at Austin, Sri Lanka

Shyama Venkateswar, Columbia University, India

Himadeep Muppidi, University of Minnesota, India

Norrin M. Ripsman, University of Pennsylvania, Canada

Erik Duchesne, Michigan State University, Canada

Howard G. Romanko, University of Arizona, Canada

Jin Yu, California Institute of Technology, P.R. China

Ming Xia, Temple University, P.R. China

Tong-yi Huang, University of Texas at Austin, Taiwain

Aurelian Craiutu, Princeton University, Romania

Ching-ping Tang, University of Southern California, Taiwain

Heajeong Lee, Northwestern University, Korea

Francisco David Rueda, Cornell University, Spain

Valentina L. Padula, University of Maryland, Italy

Henry Laurence, Harvard University, United Kingdom

Carlos Pereira, New School for Social Research, Brazil

Anibal Perez Linan, University of Notre Dame, Argentina

Jakob Zielinski, University of Chicago, Poland

Demet Yalcin, Binghamton University, Turkey

Okiyoshi Takeda, Princeton University, Japan

Juchan Kim, George Washington University, Korea

Soo Yeon Kim, Yale University, Korea 


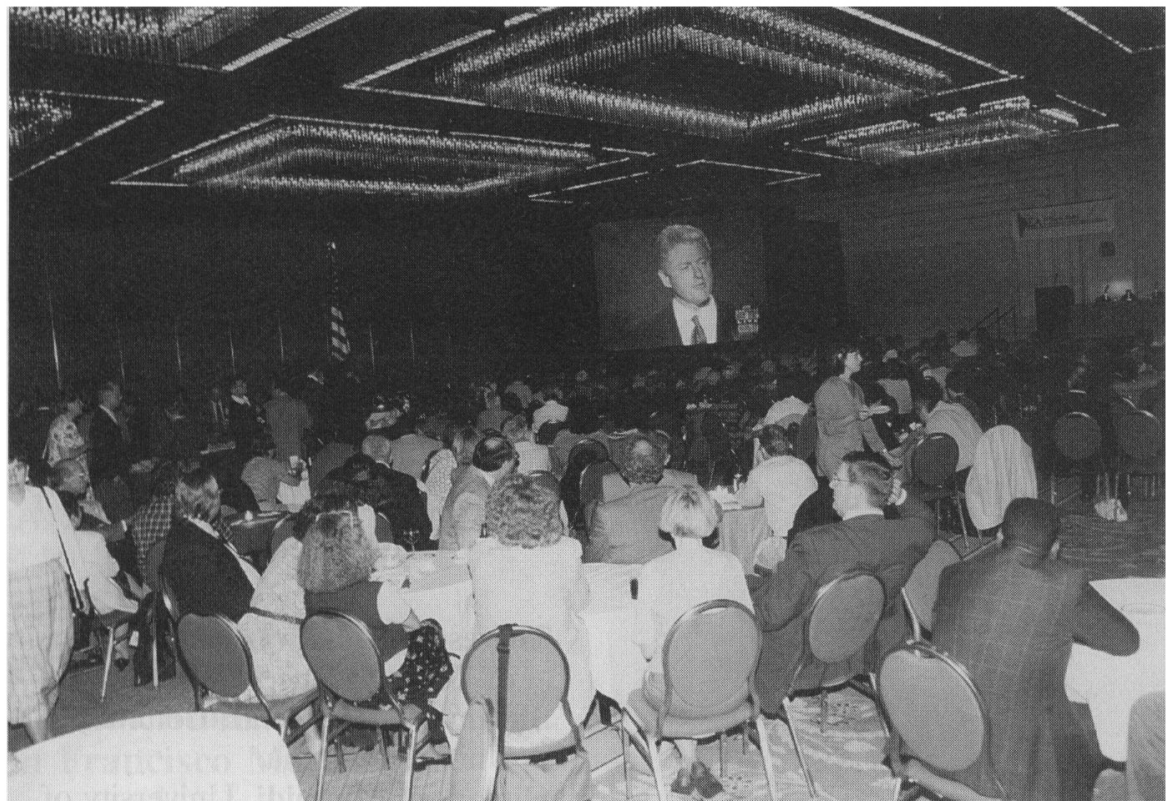

The telecast of the Clinton acceptance speech preceded the Lasswell Symposium. The dual event was cosponsored by APSA and Pi Sigma Alpha. David Magelby, President of Pi Sigma Alpha, moderated the Lasswell panel composed of Charles O. Jones, Jeffrey Tulis, Linda Faye Williams, Kathleen Hall Jamieson. Josef Joffe of Die Sueddeutsche Zeitung added an international dimension to the analysis of the Clinton Address.

\section{Senior Scholar Grants}

Iain Hampsher-Monk, Exeter University, United Kingdom

Graham Maddox, University of New England, Australia

Sally Jenkinson, University of North London, United Kingdom

Christian Shultz, University of Copenhagen, Denmark

Enriueta Aragones, Universitat pompev Fabra, Spain

Gunther Englehardt, Universitat Hamburg, Germany

Josep Colomer, Institut D'Etudes Politiques de Paris, France

Claudie Baudino, Université Paris IX-Dauphine, France

Celia Valiente, Insituto Juan March de Estudios e Investigaciones, Spain

Tim Bale, University of Sheffield, United Kingdom

Joyce Outshoorn, Rijksuniversiteit Leiden, The Netherlands

Michael Cahen, Centre d'Etude d'Afrique, France

Robert Salais, IEPE-ERESCO, France

Robert Boyer, CEPREMAP, France

Ellen Immergut, Universitat Konstanz, Germany

Catherine Hoskyns, Coventry University, United Kingdom
Evelyn Mahon, Trinity College, Ireland

A. Claire Cutler, University of Victoria, Canada

Erich Weede, University of Cologne, Germany

Wolfgang Rudig, University of Strathclyde, United Kingdom

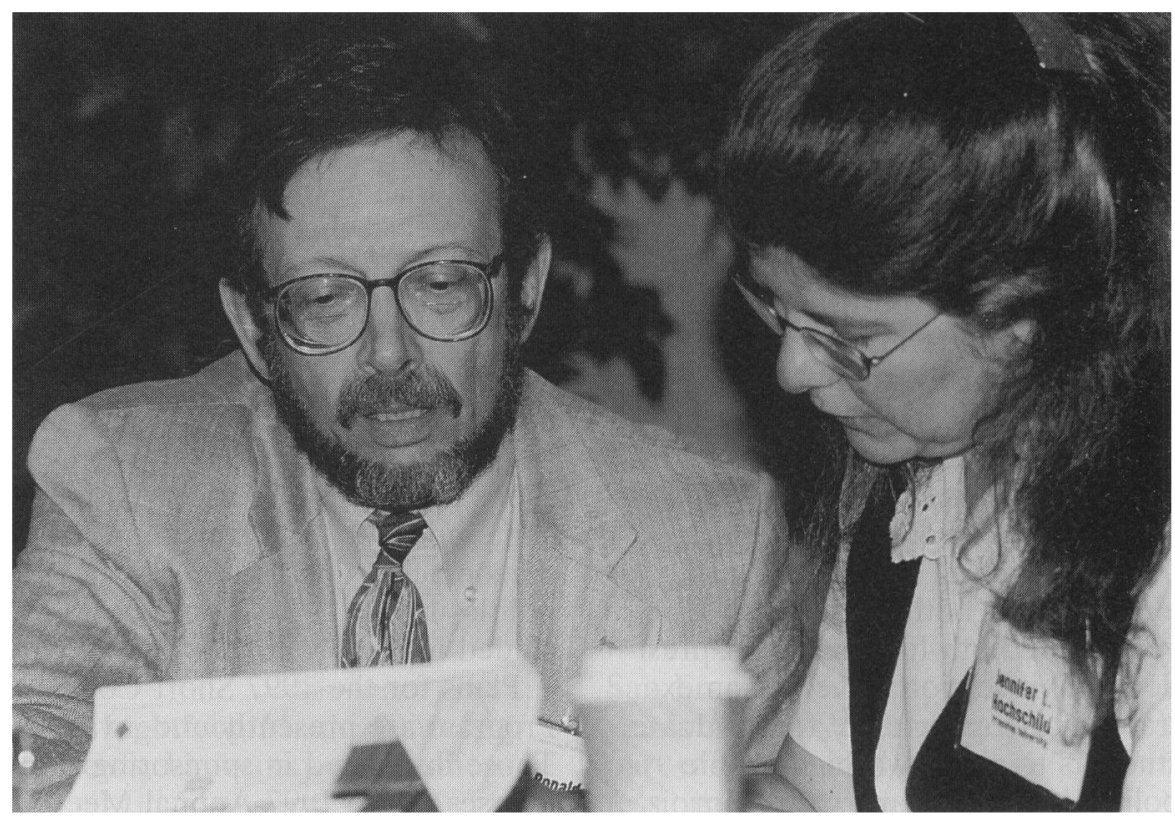

Co-chairs of the 1996 Program Committee, Ronald Rogowski, UCLA, and Jennifer Hochschild, Princeton University, still at work.
Maureen Whitebrook, University of Sheffield, United Kingdom

Bernard Crick, Birkbeck College, United Kingdom

Kiyoko Iwasaki, London School of Economics, United Kingdom

Tatania Zakharova, Priamursky Center, Khabarovsk, Russia

Fumio Iida, Kobe University

Ikuo Kabashima, Tsukuba University

\section{Section Makes Contribution to Travel Grant Program}

The growth of international participation at the APSA Annual Meeting has also increased the level of requests for financial assistance from international scholars. Recognizing the importance of international participation, the Organized Section on Women and Politics contributed $\$ 500$ to assist in travel costs of Dr. Tatania Zakharova, a recent graduate of the Academy of Public Administration in Moscow. Currently working at the Priamursky Center in Khabarovsk, Zakharova's interests lay in empirical theory, data, and hypothesis-testing.

The Association is grateful to the organization for its generous contribution and encourages others to support APSA's efforts to broaden the participation of international scholars at the Annual Meeting. 